\title{
Gradient categories in lexically-conditioned phonology: An example from sound symbolism
}

\author{
Stephanie S Shih \\ University of Southern California
}

\section{Introduction}

Sound symbolism highlights the interaction between categories and the different phonological patterns that arise between categories. Such interaction between phonologically-external categories and phonological patterns also exists in "core" morphophonology. In particular, lexically-conditioned phonology is exactly this situation, where different lexical categories often exhibit different phonotactic patterns or phonological alternations. For example, content words in English (such as nouns) are known to exhibit greater phonotactic contrasts than function words, whereas function words exhibit greater phonological reduction in running speech than content words (e.g., Selkirk 1984, 1996; Inkelas \& Zec 1993; Kelly \& Bock 1988; Kelly 1992; Segalowitz \& Lane 2000; Bell et al. 2009; Smith 2011, 2016; Shih 2014, 2018).

The categories that have been noted to be relevant for lexically-conditioned phonology in fact already include some that border on non-arbitrary patterns. While many times, lexical conditioning comes from morphosyntactically-defined categories (e.g., content versus function words; parts of speech) or arbitrary gender class systems, sometimes, categories such as ideophones or sex (e.g., male/female) also engender differences in phonological behavior. As such, sound symbolic data turns out to be a useful sandbox in which to explore phonological behaviours resulting from lexical conditioning.

This paper offers a natural extension of our existing formal model for lexically-conditioned phonology, based on patterns in sound symbolic behaviours and illustrated by a dataset of male and female American English names. The paper is organized as follows. Section 2 sets up the theoretical environment, presenting an approach to lexically-conditioned phonology in Maximum Entropy Harmonic Grammar with a toy illustration. Section 3 presents a proposal to extend this approach to gradient category memberships. Finally, $\S 4$ concludes.

\section{Lexically-conditioned phonology in Maximum Entropy Harmonic Garmmar}

There are several existing approaches to modeling lexically-conditioned phonology. These include but are not limited to lexically-indexed constraints (e.g., Ito \& Mester 1995; Pater 2000, 2009; Smith 2001), strata (e.g., Kiparsky 1982), cophonologies (e.g., Anttila 2002; Inkelas \& Zoll 2005), and sublexical grammars (e.g., Allen \& Becker 2015; Becker \& Gouskova 2016). For probabilistic lexically-conditioned phonotactic distributions, lexically-indexed constraints or cophonologies (i.e., sets of lexically-indexed constraints) are embedded in Maximum Entropy Harmonic Grammar (henceforth, MaxEnt HG) (for MaxEnt HG: see e.g., Goldwater \& Johnson 2003; Jäger 2007; Hayes \& Wilson 2008; for lexically-conditioned phonology in MaxEnt HG: see e.g., Albright 2008; Coetzee \& Pater 2011; Moore-Cantwell \& Pater 2016; Shih \& Inkelas 2016).

In MaxEnt HG, the probability of a given candidate is related to the candidate's Harmony score, as calculated in (1):

$$
\mathcal{H}(y \mid x)=\sum_{i=1}^{N} w_{i} \mathbb{C}_{i}(y, x)=w_{1} \mathbb{C}_{1}+w_{2} \mathbb{C}_{2}+\cdots+w_{n} \mathbb{C}_{n}
$$

where $y$ is the candidate for $x$, $w_{i}$ is the weight of constraint $\mathbb{C}_{i}$, $\mathbb{C}_{i}(y, x)$ is the number of violations of $\mathbb{C}_{i}$ that $(y, x)$ incurs, and $N$ is the vector of constraints $\mathbb{C}_{i} \cdots \mathbb{C}_{n}$.

\footnotetext{
* Acknowledgements to Darya Kavitskaya, Laura McPherson, Charlie O’Hara, Deniz Rudin, Brian Smith, Rachel Walker and audiences at USC, AMP 2019, NELS 50, and BLS 2020 for discussion on various portions of this work.
} 
The introduction of lexically-conditioned constraints increases the number of weights in the harmony score calculation as follows, shown in (2) in expanded form (Shih \& Inkelas 2016):

$$
\mathcal{H}(y \mid x)=w_{1} \mathbb{C}_{1}+w_{2}\left(\mathbb{C}_{1} \times \mathbb{k}_{a}\right)+w_{3}\left(\mathbb{C}_{1} \times \mathbb{k}_{b}\right)+\cdots+w_{n \cdot l}\left(\mathbb{C}_{n} \times \mathbb{k}_{l}\right),
$$

where each constraint $\mathbb{C}$ has a weight $w_{N}$ for every category $\mathbb{k}_{L}$.

Each constraint thus is duplicated for every category, and each category-indexed constraint carries a weight separate from the "base" constraint weight (i.e., the non-indexed form of the constraint).

The following section illustrates lexically-conditioned phonology using this approach.

2.1 Toy illustration: Male versus female names Phonotactic differences between male and female names in English have long been noted in the literature (e.g., Cassidy et al. 1999; Wright et al. 2005), and often pattern with sound-symbolic associations. Here, I use a dataset of the 200 most frequent male and 200 most frequent female names, from the Social Security Administration's list of American English names for U.S. births between 1990-1999. As a toy illustration, I focus on two of the strongest predictors of male and female names in the current dataset (from a list of male/female name differences from the previous literature, as tested with the MaxEntGrammarTool; Hayes et al. 2009).

In the current dataset, female names are significantly more likely to avoid final stop obstruents than male names, shown in Figure 1.

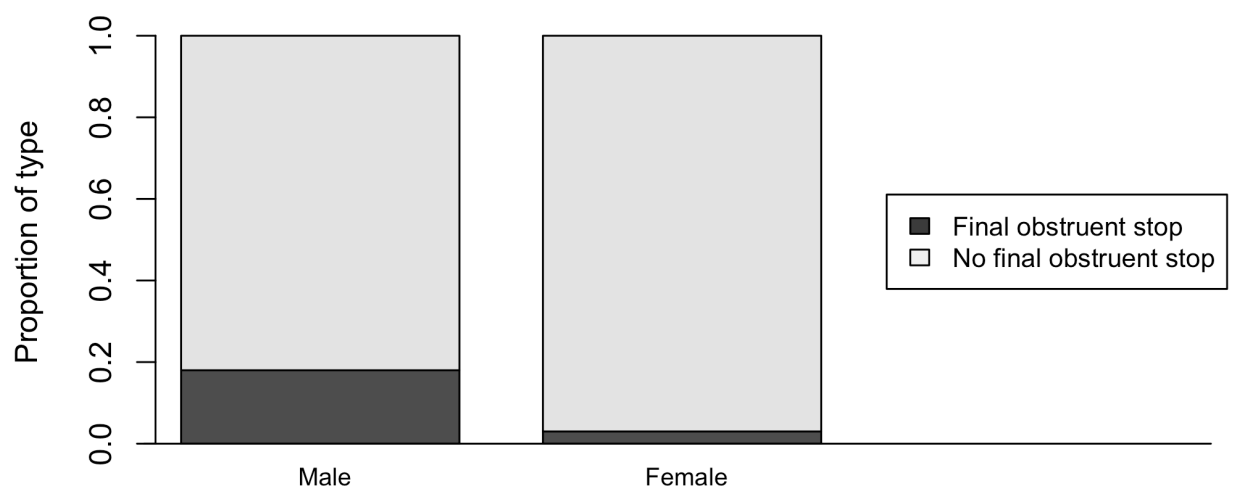

Figure 1. Name-final stop obstruent, by gender

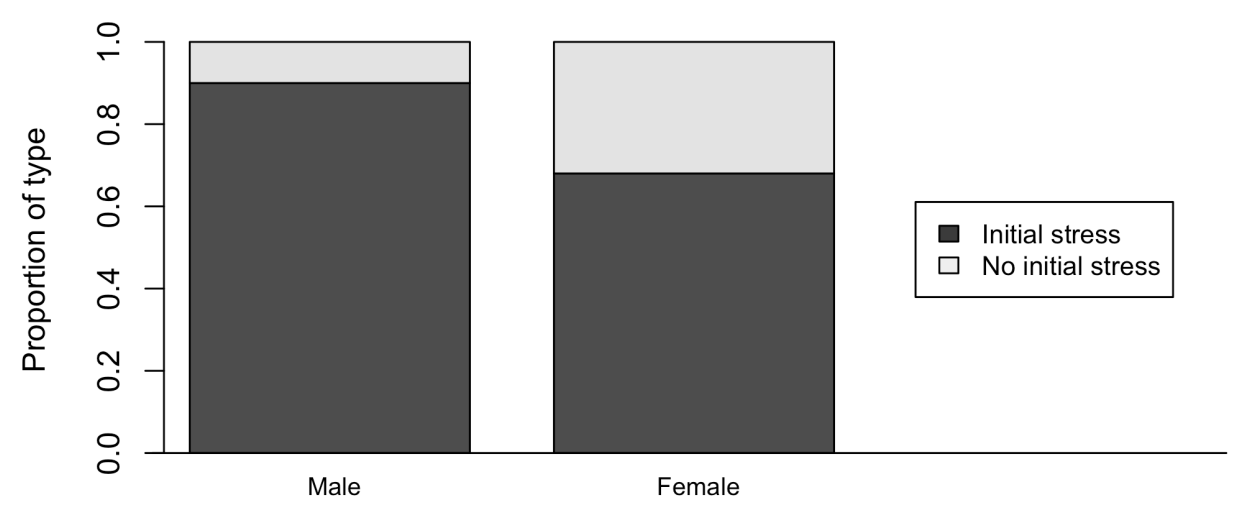

Figure 2. Initial stress in name, by gender

Male names in the dataset are significantly more likely to begin with an initial stressed syllable (i.e., roughly, be trochaic), as shown in Figure 2. For example, Elaine, a female name, is [n]-final and features iambic stress, while Albert, a male name, is [t]-final with trochaic, initial stress.

These preferences can be modeled using the following constraints (3) and (4): 
(3) $\quad * \mathrm{~T} \#$

(4) TROCH

Penalize every name that ends with a final stop obstruent.

Penalize every name that does not begin with an initial stressed syllable.

Because male and female names behave differently, there needs to be lexically-indexed versions of these constraints, weighted for each lexical class, as shown in (5):

$$
\mathcal{H}(y \mid x)=w_{1} \mathbb{C}_{1}+w_{2}\left(\mathbb{C}_{1} \times \mathbb{k}_{\text {Male }}\right)+w_{3}\left(\mathbb{C}_{1} \times \mathbb{k}_{\text {Female }}\right)+\cdots+w_{n \cdot l}\left(\mathbb{C}_{n} \times \mathbb{k}_{l}\right),
$$

The "base" grammar would thus consist of the constraints that are not lexically indexed. The cophonology for male names consists of constraints that are lexically indexed for $\mathbb{k}_{\text {Male }}$, while the cophonology for female names consists of constraints that are lexically indexed for $\mathbb{k}_{\text {Female }}$.

The tableau in (6) provides an illustration, with hand-weighted constraints, of the optimal selection for a phonological input that has the shape /CV.CVT/, given female or male name gender affiliation. A male name input is given in (6a) and a female name input is given in (6b).

\begin{tabular}{|c|c|c|c|c|c|c|c|c|c|c|}
\hline & & & $\begin{array}{c}\text { TROCH } \\
\sigma^{*}\end{array}$ & $\begin{array}{c}* \mathrm{~T} \# \\
\stackrel{9}{ }\end{array}$ & $\begin{array}{c}\text { WSP } \\
\wp\end{array}$ & TROCH & *T\# & WSP & FAITH-C & \multirow[t]{2}{*}{$\mathscr{H}$} \\
\hline & & & 3 & 3 & 2 & 1 & 1 & 1 & 2 & \\
\hline \multirow{3}{*}{$\begin{array}{l}\text { a. } \\
/ \mathrm{CV} . \mathrm{CVT} / \\
\sigma^{\prime}\end{array}$} & & 'CV.CVT & & & & & -1 & -1 & & -2 \\
\hline & & CV.'CVN & -1 & & & -1 & & & -1 & -6 \\
\hline & & CV.CVN & & & & & & -1 & -1 & -3 \\
\hline \multirow{3}{*}{$\begin{array}{l}\mathrm{b} . \\
/ \mathrm{CV} . \mathrm{CVT} / \\
q\end{array}$} & & "CV.CVT & & -1 &  & & -1 & 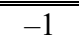 & & -7 \\
\hline & & CV.'CVN & & & & -1 & & & -1 & -3 \\
\hline & & CV.CVN & & & -1 & & & -1 & -1 & -5 \\
\hline
\end{tabular}

As shown in (6), a lexically-indexed TROCH o constraint to male names is contributes an additional weight, and rules out any iambic candidates (CV. ' CVN). In the same grammar, base TROCH cannot be weighted too high because iambic candidates do win-just not in the male name portion of the grammar. There are also two constraints indexed for female names: ${ }^{*} \mathrm{~T} \#$ \% and WSP $\%$. The former provides extra penalization for name-final stop obstruents, as in the candidate 'CV.CVT. The female name-specific WSP $\%$ ensures the algebraically-higher harmony score for a candidate with iambic stress on the heavy final syllable, versus trochaic stress.

Thus far, the currently-available approaches to lexically-conditioned phonology appear to work well, even for patterns originating from sound symbolism, as demonstrated by the male and female name toy illustration. Naturally-occurring sound symbolic patterns, however, require more gradience in category structures, as demonstrated by the case studies in the following section.

\section{Theoretical ramifications: Gradient lexical category membership}

As presented in $\S 2$, there are a number of existing approaches to lexically-conditioned phonology, including lexically-indexed constraints, strata, cophonologies, and sublexical grammars. One feature that nearly all of these approaches share is the assumption of crisp, discrete boundaries in lexical category membership. For instance, a word belongs either to the content word or function word class; a part of speech is either noun or verb; a morpheme is Latinate or not; a name is either male or female. Even analyses that use lexically-indexed constraints for the "expressive" lexicon assume this type of rigid category membership at work (e.g., Alderete \& Kochetov 2016; Kawahara et al. 2019).

Recent work in sound symbolism, however, has demonstrated that not all behaviours correspond to crisply delineated category membership. For example, work on sound symbolic correspondences between Pokémon names and their characteristics have demonstrated phonotactic patterns that scale with how evolved, how heavy, and how tall a character is (e.g., Kawahara et al. 2018; Kawahara \& Moore 2018; Shih et al. 2018, 2019; Kawahara \& Kumagai 2019): e.g., longer Pokémon names correspond with heavier Pokémon. Similar quantitative patterns have also been noted in a corpus of American Major League Baseball players (Shih \& Rudin 2019). Many of these categories that correspond to sound symbolic phonotactic patterns are not categorical: for example, weight, height, power for both Pokémon and baseball players. Non- 
categoricity in category membership is in fact not a new issue in linguistics. See, for instance, the rich literature on scale structure in semantics (e.g., Kennedy \& McNally 2005), which notes that some adjectives allow categorical membership (e.g., an entity can be either alive or dead, but not both or in between) whereas others do not have as clear-cut distinctions (e.g., whether an entity is tall can vary).

How, then, do our grammatical models handle gradient category membership in lexically-conditioned phonology if the existing mechanisms that we have assume categorical (i.e., full or none) membership? One option is to posit a potentially infinite number of categorical cuts along a scale relevant for phonology. This approach, however, would be computationally rather inefficient, and it ignores the gradient or scalar nature of many category types. ${ }^{1}$

Alternatively, we can allow gradience in the category structures that the phonological grammar operates over. Scaling and gradience have been shown in recent literature to be necessary in many parts of phonological grammar and representation. Notably, gradient symbolic activations have been used to capture phonological elements that have blended representations, where a segment can be co-activated for conflicting feature representations (Smolensky et al. 2014; Smolensky \& Goldrick 2016). The proposal here is that category membership can also have gradient symbolic activations ${ }^{2}$; the harmony calculation from (2) has been updated in (7) accordingly.

$$
\mathcal{H}(y \mid x)=w_{1} \mathbb{C}_{1}+w_{2}\left(\mathbb{C}_{1} \times \mathbb{k}_{a}\right)+w_{3}\left(\mathbb{C}_{1} \times \mathbb{k}_{b}\right)+\cdots+w_{n \cdot l}\left(\mathbb{C}_{n} \times \mathbb{k}_{l}\right)
$$

where each constraint $\mathbb{C}$ has a weight $w_{N}$ for every category $\mathbb{k}_{L}$, and where each $\mathbb{k}_{l} \in[0,1]$.

Each input, then, is associated with a gradient activation for every category. Weighted category membership is not new to maximum entropy models outside of linguistics: multiple membership multilevel models use a similar structure to model mixed and multiple membership of individuals in groups (e.g., Browne et al. 2001), and are particularly useful in social network membership modeling (e.g., Tranmer et al. 2014).

An example tableau is given in (8). Input 1 has a category $\mathbb{k}$ activation of 0.9 , whereas Input 2 has a category $\mathbb{k}$ activation of 0.2 . The same Candidate $A$, then, which violates category-indexed constraint $\mathbb{C}_{\mathbb{k}}$, will have a different scores for the two inputs: Candidate A's violation will be multiplied by 0.9 for Input 1 and by 0.2 for Input 2 . Candidate A will consequently be a more harmonic candidate for Input 2 than for Input 1.

\begin{tabular}{|l||c||c||c|}
\hline \multicolumn{1}{|c||}{} & & $\mathbb{C}_{\mathbb{k}}$ & \\
\cline { 3 - 3 } & & 1 & $\mathscr{H}$ \\
\hline \hline a. input $1, \mathbb{k}_{\mathbb{k}}=0.9$ & candidate A & $-1^{*} 0.9$ & -0.9 \\
\hline \hline b. input $2, \mathbb{k}=0.2$ & candidate A & $-1^{*} 0.2$ & -0.2 \\
\hline
\end{tabular}

Gradient symbolic activations over category membership predict that we should find phonological behaviours that fall between categorical behaviours. I now return to the toy illustration from $\S 2.1$.

3.1 Revisiting the toy illustration: Male versus female names As discussed in $\S 2.1$, male and female names exhibit phonotactic differences. However, gender categories are much more fluid, particularly in the 1990 s, with the rise of unisex or gender-neutral names. In order to compare a "unisex" set to the most frequent male and female names, 200 of the most frequent names used for either male or female genders no more than $69 \%$ of the time were taken from the same 1990-1999 Social Security Administration dataset.

The behaviour of these unisex names is as predicted: they pattern between male and female name phonotactic preferences. As shown in Figure 3, unisex names avoid final stop obstruents less often than female names, but still more often than male names (compare, for example, Taylor to Elaine and Albert).

\footnotetext{
${ }^{1}$ To be sure, we do need to be able to posit new categories; however, it has been shown (statistically, at least) that new categories are formed only when there is sufficient evidence to do so (e.g., in psychology: Ahn \& Medin 1992; in morphosyntactic categories: Shih 2018).

${ }^{2}$ see e.g., Goldrick et al. 2016 for gradient symbolic activations beyond phonological elements.
} 


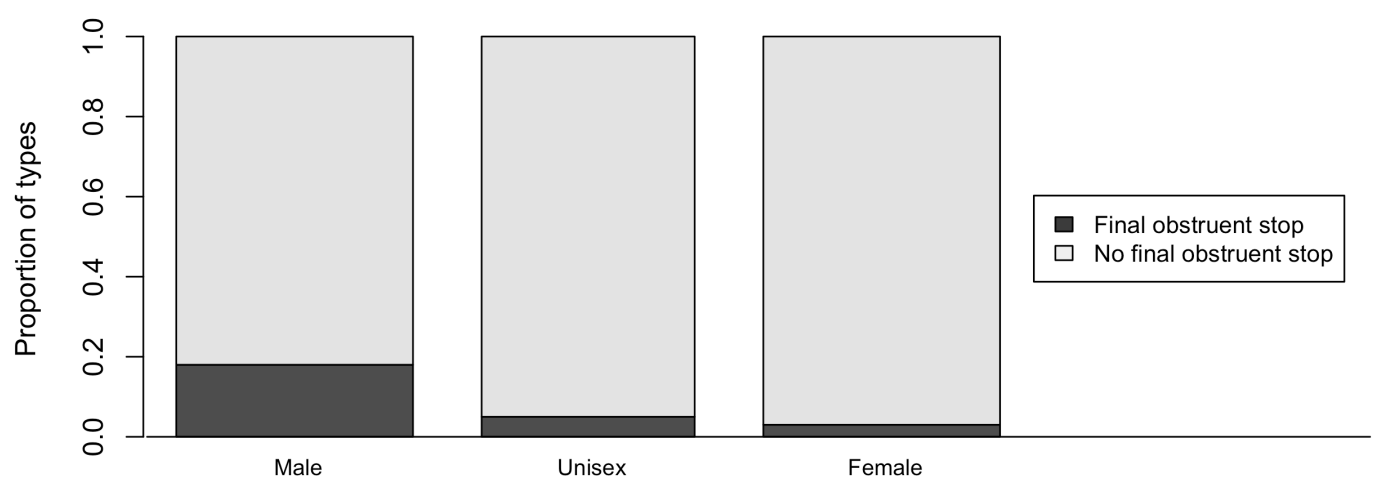

Figure 3. Name-final stop obstruent, by gender (Width of bars are scaled by proportion of data)

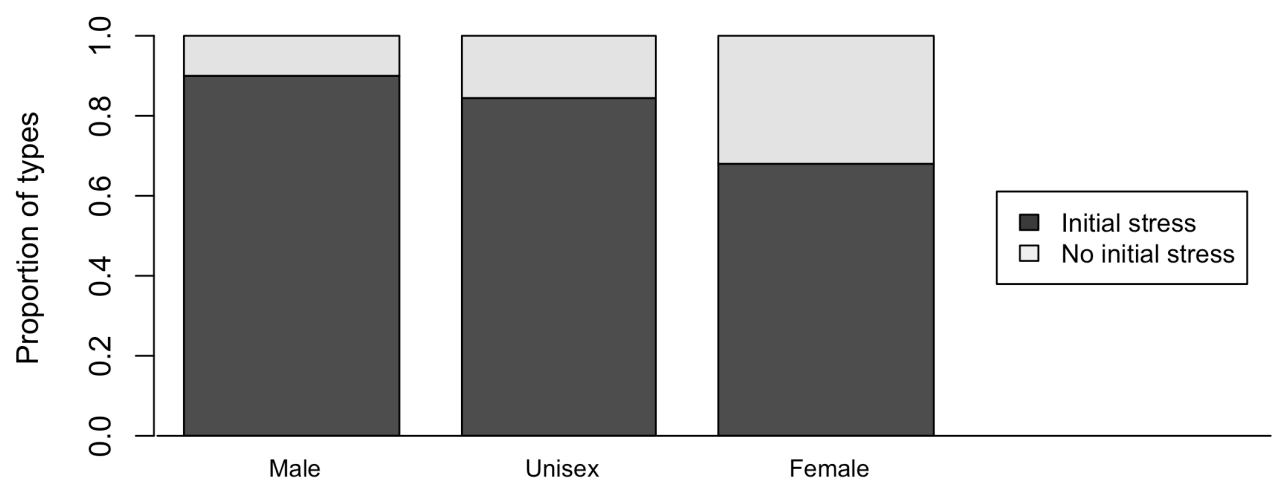

Figure 4. Initial stress in name, by gender (Width of bars are scaled by proportion of data)

Figure 4 shows that unisex names are more likely to have initial stress than female names, but less likely than male names.

These patterns can be modeled in the mixed membership MaxEnt HG by specifying a blended activation for unisex names. A demonstrative, hand-weighted tableau is given in (9).

(9)

\begin{tabular}{|c|c|c|c|c|c|c|c|c|c|}
\hline & & $\begin{array}{c}\text { TROCH } \\
O^{*} \\
\end{array}$ & $\begin{array}{c}*{ }^{*} \mathrm{~T} \# \\
\% \\
\end{array}$ & 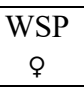 & TROCH & *T\# & WSP & $\begin{array}{c}\text { FAITH- } \\
\text { C }\end{array}$ & \multirow[t]{2}{*}{$\mathscr{H}$} \\
\hline & & 3 & 3 & 2 & 1 & 1 & 1 & 2 & \\
\hline \multirow{3}{*}{$\begin{array}{l}\text { a. } \\
/ C V . C V T / \\
O^{\prime \prime}=1,(\&=0)\end{array}$} & 'CV.CVT & & & & & $\begin{array}{ll}-1 \\
\end{array}$ & -1 & & -2 \\
\hline & CV.'CVN & -1 & & & -1 & & & -1 & -6 \\
\hline & CV.CVN & & & & & & -1 & -1 & -3 \\
\hline \multirow{3}{*}{$\begin{array}{l}\mathrm{b} . \\
/ \mathrm{CV} \cdot \mathrm{CVT} / \\
\left(\boldsymbol{O}^{*}=1\right), Q=0\end{array}$} & "CV.CVT & & -1 & -1 & & -1 & -1 & & -7 \\
\hline & CV.'CVN & & & & -1 & & & -1 & -3 \\
\hline & 'CV.CVN & & & -1 & & & -1 & -1 & -5 \\
\hline \multirow{3}{*}{ 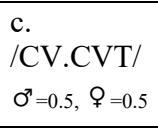 } & "CV.CVT & & -0.5 & -0.5 & & $\begin{array}{l}-1 \\
\end{array}$ & -1 & & -4.5 \\
\hline & CV.'CVN & -0.5 & & & -1 & & & -1 & -4.5 \\
\hline & 'CV.CVN & & & -0.5 & & & -1 & -1 & -4 \\
\hline
\end{tabular}

In (9), a male name input has an activation of 1 of the male category $\left(\sigma^{\top}=1\right)$, while a female name input has an activation of 1 in the female category. A unisex name, which is used for either male or female (as specified by the Social Security Administration data, which is, to date, gender-binary), has a blended activation for both categories. Thus, the lexically-indexed constraints for both categories apply and the optimal candidate 
is one that has blended features-in this illustration, a name that is trochaic and avoids name-final stop obstruents. $^{3}$

\section{Conclusion}

Do we need such gradient category membership outside of sound symbolic patterns? Categories in "core" phenomena of lexically-conditioned phonology also exhibit similar gradient behaviours. For example, auxiliary verbs such as can, could, might, must in English often have duality in their phonological behaviours: they act like content words in hosting greater phonotactic contrasts, but they also act like function words in their propensities to reduce (compared to full verbs) in running speech. To deal with cases like this, previous research has often posited that the relevant categories are more than just "content" and "function" classes of words, resulting in anywhere from 4 to 10 categories along the content to function spectrum (e.g., Altenberg 1987; Hirschberg 1993; Shih 2014; Anttila 2017). However, under a gradient category membership approach, a binary category specification can be salvaged.

The abstraction of form as separate from meaning or concept has been foundational to modern linguistic study, as codified by the assumption of the arbitrariness of the sign. One consequence of the assumed division between form and meaning in linguistic study has been the significant overlooking of "non-arbitrary" data such as sound symbolic phenomena in the realm of formal theory. In the minority is work that maintains that non-arbitrary patterns can be and should be captured using formal phonological models. At the very least, much of this work still treats the question of whether non-arbitrary patterns should be in the grammar as still open and unsettled (e.g., on modeling palatalization in formal phonological grammars: Mester \& Ito 1989; Alderete \& Kochetov 2016; on sound symbolism in Maximum Entropy Harmonic Grammar: Kawahara et al. 2019; on the grammatical status of ideophones: Newman 2001; Dingemanse 2012; Rose 2015; Shih \& Inkelas 2016; a.o.). This paper offers another argument that sound symbolic patterns, in spite of their nonarbitrary roots, are not as extraordinary from "core" phonological patterns as traditionally believed: sound symbolic phenomena can parallel the phonological patterns that our "core" phonological grammars already capture, particularly in how we deal with lexically-conditioned phonology.

\section{References}

Ahn, Woo-Kyoung; and Douglas L. Medin. 1992. A two-stage model of category construction. Cognitiive Science $16.81-121$.

Albright, AdAm. 2008. How many grammars am I holding up? Discovering differences between word classes. Proceedings of the 26th West Coast Conference on Formal Linguistics, ed. by Charles B. Chang and Hannah J. Haynie, 1-20. Somerville, MA: Cascadilla Proceedings Project.

Alderete, John; and AleXei Kochetov. 2016. Integrating sound symbolism with core grammar: The case of expressive palatalization. Language.

Allen, Blake; and Michael BecKer. 2015. Learning alternations from surface forms with sublexical phonology. Manuscript. lingbuzz/002503.

Altenberg, Bengt. 1987. Prosodic patterns in spoken English: Studies in the correlation between prosody and grammar for text-to-speech conversion. Lund Studies in English 76. Sweden: Lund University Press.

AntTila, ARTO. 2002. Morphologically Conditioned Phonological Alternations. Natural Language \& Linguistic Theory 20.1-42.

AntTILA, ARTO. 2017. Stress, Phrasing, and Auxiliary Contraction in English. The morphosyntax-phonology connection: Locality and directionality at the interface, ed. by Vera Gribanova and Stephanie S Shih, 143-170. Oxford, UK: Oxford University Press.

Becker, Michael; and Maria Gouskova. 2016. Source-oriented generalizations as grammar inference in Russian vowel deletion. LInguistic Inquiry 47.391-425.

\footnotetext{
${ }^{3}$ Names from the decade 1990-1999 were used because this decade saw a rise in unisex name use: with wider acceptance of gender non-binarity after the $2000 \mathrm{~s}$, it is possible that gender-neutral or unisex names no longer have blended activations of male and female categories but their own category features. That is, it is possible that we now have a separate category or categories for non-male and non-female-identifying names.
} 
Bell, Alan; Jason M. Brenier; Michelle Gregory; Cynthia Girand; and Daniel Jurafsky. 2009. Predictability effects on durations of content and function words in conversational English. Journal of Memory and Language $60.92-111$.

Bremner, Andrew J.; Serge Caparos; Jules Davidoff; Jan de Fockert; Karina J. Linnell; and Charles Spence. 2013. "Bouba" and "Kiki" in Namibia? A remote culture make similar shape-sound matches, but different shape-taste matches to Westerners. Cognition 126.165-172. doi:10.1016/j.cognition.2012.09.007.

Browne, William J; Harvey Goldstein; and Jon Rasbash. 2001. Multiple membership multiple classification (MMMC) models. Statistical Modelling 1.103-124. doi:10.1177/1471082X0100100202.

Cassidy, Kimberly Wright; Michael H. Kelly; and LeE’at J. Sharoni. 1999. Inferring gender from name phonology. Journal of Experimental Psychology: General 128.362-381. doi:DOI:10.1037/0096-3445.128.3.362.

Coetzee, Andries W; and Joe Pater. 2011. The place of variation in phonological theory. The Handbook of Phonological Theory, ed. by John Goldsmith, Jason Riggle, and Alan Yu, 401-431. 2nd Edition. Cambridge: Blackwell.

Dingemanse, Mark. 2012. Advances in the Cross-Linguistic Study of Ideophones. Language and Linguistics Compass $6.654-672$.

Dingemanse, Mark; Damián E. Blasi; Gary Lupyan; Morten H. Christiansen; and Padraic Monaghan. 2015. Arbitrariness, Iconicity, and Systematicity in Language. Trends in Cognitive Sciences 19.603-615.

Goldrick, Matthew; Michael Putnam; and Lara Schwarz. 2016. Coactivation in bilingual grammars: A computational account of code mixing*. Bilingualism: Language and Cognition 19.857-876. doi:10.1017/S1366728915000802.

GoldwATER, SHARON; and MARK Johnson. 2003. Learning OT Constraint Rankings Using a Maximum Entropy Model. Proceedings of the Stockholm Workshop on Variation within Optimality Theory, ed. by Jennifer Spenader, Anders Eriksson, and Östen Dahl, 111-120. Stockholm: Stockholm University.

Hayes, Bruce; and Colin Wilson. 2008. A maximum entropy model of phonotactics and phonotactic learning. Linguistic Inquiry 39.379-440.

Hayes, Bruce; Colin Wilson; and Ben George. 2009. Maxent Grammar Tool. http://www.linguistics.ucla.edu/people/hayes/MaxentGrammarTool/.

Hinton, Leanne; Johanna Nichols; and John OHALA. 1994. Sound-symbolic processes. Sound symbolism, ed. by Leanne Hinton, Johanna Nichols, and John J. Ohala, 1-14. Cambridge, UK: Cambridge University Press.

HirschberG, Julia. 1993. Pitch accent in context: predicting intonational prominence from text. Artificial Intelligence 63.305-340.

InKelas, Sharon; and Draga Zec. 1993. Auxiliary reduction without empty categories: a prosodic account. Working Papers of the Cornell Phonetics Laboratory, 205-254. 8. Cornell University.

INKELAS, SHARON; and CHERYL ZOLL. 2005. Reduplication: doubling in morphology. Cambridge: Cambridge University Press.

Ito, JunKo; and ARmin Mester. 1995. Japanese phonology. Handbook of Phonological Theory, ed. by John Goldsmith, 817-838. Cambridge, Mass.: Blackwell.

JÄGer, Gerhard. 2007. Maximum Entropy Models and Stochastic Optimality Theory. Architectures, Rules, and Preferences: A Festschrift for Joan Bresnan, ed. by Jane Grimshaw, Joan Maling, Chris Manning, Jane Simpson, and Annie Zaenen. Stanford, CA: CSLI.

Kawahara, Shigeto; Hironori Katsuda; and Gakuji Kumagai. 2019. Accounting for the stochastic nature of sound symbolism using Maximum Entropy model. Open Linguistics 5.109-120.

Kawahara, Shigeto; and Gakuji Kumagai. 2019. Expressing Evolution in Pokémon Names: Experimental Explorations. Journal of Japanese Linguistics 35.3-38. doi:https://doi-org.libproxy2.usc.edu/10.1515/jj1-20192002.

Kawahara, Shigeto; and Jeff Moore. 2018. Exploring sound symbolic knowledge of English speakers using Pokémon character names. Ms. Keio University \& Sophia University, ms. https://ling.auf.net/lingbuzz/004143.

Kawahara, Shigeto; Atsushi Noto; and Gakuji Kumagai. 2018. Sound symbolic patterns in Pokémon names. Phonetica 75.219-244.

Kelly, Michael H. 1992. Using sound to solve syntactic problems: The role of phonology in grammatical category assignments. Psychological Review 99.349-364. doi:10.1037/0033-295X.99.2.349.

Kelly, Michael H.; and J. Kathryn Bock. 1988. Stress in time. Journal of Experimental Psychology: Human Perception and Performance 14.389-403. doi:10.1037/0096-1523.14.3.389.

Kennedy, Christopher; and Louise McNally. 2005. Scale Structure, Degree Modification, and the Semantics of Gradable Predicates. Language 81.345-381.

KiPARSKY, PAul. 1982. Lexical Morphology and Phonology. Linguistics in the Morning Calm, ed. by I. -S. Yang, 2:391. Seoul: Hanshin Publishing Company.

Mester, Armin; and Junko Ito. 1989. Feature Predictability and Underspecification: Palatal Prosody in Japanese Mimetics. Language 65.258-293.

Moore-Cantwell, Claire; and Joe Pater. 2016. Gradient Exceptionality in Maximum Entropy Grammar with Lexically Specific Constraints. Catalan Journal of Linguistics 15.53. doi:10.5565/rev/catjl.183. 
Newman, Paul. 2001. Are ideophones really as weird and extra-systematic as linguists make them to be? Ideophones, ed. by F. K. Erhard Voeltz and Christa Kilian-Hatz, 251-258. Typological Studies in Language 44. Amsterdam: John Benjamins.

PATER, JOE. 2000. Non-uniformity in English secondary stress: the role of ranked and lexically specific constraints. Phonology 17.237-274.

PAter, Joe. 2009. Morpheme-specific phonology: constraint indexation and inconsistency resolution. Phonological argumentation: essays on evidence and motivation, ed. by Steve Parker. Advances in Optimality Theory. Equinox.

Rose, Sharon. 2015. Phonology of Ideophones in African Languages. Paper. Paper presented at the WOCAL 8, Kyoto University, Japan.

SEgalowitz, Sidney J.; and KorRi C. LANe. 2000. Lexical access of function versus content words. Brain and Language 75.376-389. doi:10.1006/brln.2000.2361.

SElkiRK, ElisaBeth. 1996. The prosodic structure of function words. Signal to Syntax: Bootstrapping from Speech to Grammar in Early Acquisition, ed. by James L Morgan, Katherine Demuth, James L Morgan, and Katherine Demuth, 187-214. Lawrence Erlbaum Associates.

SElkiRK, ElisABeth O. 1984. Phonology and syntax: The relation between sound and structure. Cambridge, MA: The MIT Press.

Shih, Stephanie S. 2014. Towards Optimal Rhythm. Stanford, CA: Stanford University PhD dissertation.

SHiH, StePhANiE S. 2018. Learning lexical classes from variable phonology. ICU Working Papers in Linguistics 4 : Selected Papers from Asian Junior Linguistics Conference 2, ed. by Yuki Seo and Haruya Ogawa, 1-15. Tokyo, Japan: International Christian University. http://id.nii.ac.jp/1130/00004363/.

Shih, Stephanie S; Jordan AcKerman; Noah Hermalin; Sharon Inkelas; Hayeun Jang; Jessica Johnson; Darya KAvitSkAYA; et al. 2019. Cross-linguistic and language-specific sound symbolism: Pokémonastics. Manuscript. University of Southern California, ms.

Shim, Stephanie S; Jordan Ackerman; Noah Hermalin; Sharon Inkelas; and Darya Kavitskaya. 2018. Pokémonikers: A study of sound symbolism and Pokémon names. Proceedings of the Linguistic Society of America 3.1-6. doi:http://dx.doi.org/10.3765/plsa.v3i1.4335.

Shih, Stephanie S; and Sharon InKelas. 2016. Morphologically-conditioned tonotactics in multilevel Maximum Entropy grammar. Proceedings of the 2015 Annual Meeting on Phonology. Washington, D.C.: Linguistic Society of America. doi:http://dx.doi.org/10.3765/amp.v3i0.3659.

Shin, Stephanie S; and Deniz Rudin. 2019. On sound symbolism in baseball player names. Manuscript. University of Southern California, ms. lingbuzz/004689.

Smith, JenNifer L. 2001. Lexical category and phonological contrast. Papers in Experimental and Theoretical Linguistics 6: Proceedings of the Workshop on the Lexicon in Phonetics and Phonology, ed. by Robert Kirchner, Joe Pater, and Wolf Wikely, 61-72. Edmonton: University of Alberta.

Smith, Jennifer L. 2011. Category-specific effects. The Blackwell Companion to Phonology, ed. by Marc van Oostendorp, Colin Ewen, Elizabeth Hume, and Keren Rice, 2439-2463. Malden, MA: Wiley-Blackwell.

SMith, JENNIFER L. 2016. Segmental noun/verb phonotactic differences are productive too. Proceedings of the Linguistic Society of America, ed. by Patrick Farrell, 1:article \#3717. Washington, DC: Linguistic Society of America. http://journals.linguisticsociety.org/proceedings/index.php/PLSA/article/view/3717.

Smolensky, PAUl; and MATTHEW GoldRick. 2016. Gradient Symbolic Representations in Grammar: The case of French liaison. Ms. ROA-1552.

Smolensky, Paul; Matthew Goldrick; and Donald Mathis. 2014. Optimization and Quantization in Gradient Symbol Systems: A Framework for Integrating the Continuous and the Discrete in Cognition. Cognitive Science 38.1102-1138.

Tranmer, Mark; David Steel; and William J Browne. 2014. Multiple-membership multiple-classification models for social network and group dependences. Journal of the Royal Statistical Society. Series A, (Statistics in Society) 177.439-455. doi:10.1111/rssa.12021.

Wright, Saundra K.; Jennifer Hay; and Tessa Bent. 2005. Ladies first? Phonology, frequency, and the naming conspiracy. Linguistics 43.531-561. 